\title{
TIC NA GESTÃO EDUCACIONAL: EFETIVIDADE NA ACADEMIA
}

\section{LAS TIC EN LA GESTIÓN EDUCATIVA: EFECTIVIDAD EN LA ACADEMIA}

\section{ICT IN EDUCATIONAL MANAGEMENT: EFFECTIVENESS IN ACADEMY}

\author{
Geovane Rafael THEISEN ${ }^{1}$ \\ Sílvia Maria de Oliveira PAVÃO ${ }^{2}$ \\ Ana Cláudia Oliveira PAVÃO ${ }^{3}$
}

\begin{abstract}
RESUMO: Este estudo é resultante de um trabalho de monografia e objetivou avaliar a contribuição das Tecnologias da Informação e da Comunicação - TIC em um curso de pósgraduação em gestão educacional, a partir da percepção dos discentes. Caracteriza-se como uma pesquisa aplicada, com abordagem qualitativa, do tipo descritivo e exploratório. $\mathrm{O}$ instrumento de pesquisa foi um questionário de avaliação, adaptado de Bertolin e Marchi (2010). Para a análise dos dados utilizou-se a análise categorial de Bardin (2011). Constatouse que os discentes avaliaram o curso como "bom", havendo consenso no uso de recursos tecnológicos e desenvolvimento de habilidades em TIC. No entanto, percebeu-se que alguns recursos necessitam de aprimoramentos quando inseridos nas aulas, pois apenas o investimento em TIC não ocasiona mudanças. É necessário, também, desenvolvimento profissional do corpo docente para a utilização pedagógica e crítica das TIC nos processos de ensino e aprendizagem, a fim de provocar mudanças e reflexões significativas.
\end{abstract}

PALAVRAS-CHAVE: Gestão. Educação. TIC. Formação.

RESUMEN: Este estudio es el resultado de una monografía y tuvo como objetivo evaluar el aporte de las Tecnologías de la Información y la Comunicación - TIC en un posgrado en gestión educativa, desde la percepción de los estudiantes. Se caracteriza por ser una investigación aplicada, con enfoque cualitativo, de tipo descriptivo y exploratorio. El instrumento de investigación fue un cuestionario de evaluación, adaptado de Bertolin y Marchi (2010). Para el análisis de datos se utilizó el análisis categórico de Bardin (2011). Se verificó que los estudiantes califican el curso como "bueno" y existe un consenso en el uso de recursos tecnológicos y desarrollo de habilidades TIC. Sin embargo, se advirtió que algunos recursos necesitan mejorar al insertarse en las clases, ya que solo la inversión en TIC no genera cambios. También existe la necesidad de un desarrollo profesional de los docentes para el uso pedagógico y crítico de las TIC en los procesos de enseñanza y aprendizaje, con el fin de provocar cambios y reflexiones significativas.

PALABRAS CLAVE: Gestión. Educación. TIC. Formación.

${ }^{1}$ Universidade Federal de Santa Maria (UFSM), Santa Maria - RS - Brasil. Doutorando no Programa de PósGraduação em Educação. ORCID: https://orcid.org/0000-0001-6075-0805. E-mail: geovane_theisen@hotmail.com

${ }^{2}$ Universidade Federal de Santa Maria (UFSM), Santa Maria - RS - Brasil. Professora no Departamento de Fundamentos da Educação. Doutorado em Educação (UAB) - Espanha. ORCID: https://orcid.org/0000-00025365-0280. E-mail: silviamariapavao@gmail.com

${ }^{3}$ Universidade Federal de Santa Maria (UFSM), Santa Maria - RS - Brasil. Professora no Departamento de Educação Especial. Doutorado em Informática na Educação (UFRGS). ORCID: https://orcid.org/0000-00029914-3700. E-mail: anaclaudiaoliveirapavao@gmail.com

RPGE- Revista on line de Política e Gestão Educacional, Araraquara, v. 25, n. 2, p. 1264-1281, maio/ago. 2021. e-ISSN: 1519-9029 DOI: https://doi.org/10.22633/rpge.v25i2.14576 
ABSTRACT: This study is the result of a monograph that aims to evaluate the contribution of Information and Communication Technologies - ICT in a postgraduate course in educational management, from the student's perception. It's characterized as applied research, with a qualitative approach, of the descriptive and exploratory type. The research instrument was an evaluation questionnaire, adapted from Bertolin and Marchi (2010). For the analysis of the data, was used the categorical analysis of Bardin (2011). It was found that the students rated the course as "good", with a consensus on the use of technological resources and the development of ICT skills. However, it was noticed that some resources need improvement when inserted in the classes because only the investment in ICT does not cause changes. There is also a need for the professional development of the teaching staff for the pedagogical and critical use of ICT in the teaching and learning processes, causing significant changes and reflections.

KEYWORDS: Management. Education. ICT. Formation.

\section{Introdução}

As Tecnologias da Informação e da Comunicação-TIC gradualmente vem ocupando espaços na academia como apoio didático-pedagógico. Razão pela qual, Barcelos, Passerino e Behar (2011) ressaltam a importância da preparação dos professores para que possam integrar as tecnologias em suas práticas docentes e ratificam a necessidade da criação de novas propostas para integração das tecnologias digitais no processo de ensino e aprendizagem. Esses processos repercutem na gestão educacional, na organização dos processos de ensino ou de aprendizagem.

Em contrapartida, o termo gestão é citado na Constituição de 1998 (BRASIL, 1988), na Lei de Diretrizes e Bases da Educação Nacional- LDB (BRASIL, 1996) e em outros instrumentos legais dos sistemas de ensino do país. Para Dias (2002, p. 11), "gestão é lançar mão de todas as funções e conhecimentos necessários para através de pessoas atingir os objetivos de uma organização de forma eficiente e eficaz".

Já no universo dos linguistas, gestão e administração são considerados sinônimos (DIAS, 2002). Em consonância com essa abordagem, há um entendimento que gestão seria um termo mais amplo que administração, pois se vincula aos processos de participação, política e democracia na escola.

Dourado (2001) corrobora com a concepção de uma gestão democrática e participativa como forma de contribuir com os preceitos da formação cidadã. Idealmente a Constituição Federal Brasileira (BRASIL, 1988) e a LDB (BRASIL, 1996) estabelecem a gestão democrática como o modo próprio de gerir as escolas públicas e os sistemas de ensino. 
A apropriação de recursos tecnológicos, por parte dos gestores para o aperfeiçoamento da prestação de serviços nas instituições de ensino pode colaborar com o desenvolvimento de uma gestão compartilhada ou em rede, dado o alcance permitido com seu uso. À vista disso, o problema dessa pesquisa partiu da seguinte indagação: o uso de TIC na formação dos professores em gestão educacional é capaz de subsidiar o processo de gestão nas escolas em que atuam ou irão atuar?

Para responder ao problema, o objetivo geral foi delineado a partir do entendimento que o conhecimento sobre o uso das TIC exerce algum impacto nos processos de gestão. Assim, se objetivou avaliar a contribuição das TIC na gestão educacional, cujos desdobramentos específicos incidiram sobre: investigar o uso de recursos tecnológicos no cotidiano educacional (ambiente/software de aprendizagem, recursos de videoconferência) e apurar o nível de motivação para a aquisição de habilidades em TIC, tais como: o uso de computador, dispositivos móveis, entre outros.

A importância científica para a execução desta pesquisa vinculou-se à gestão educacional, considerando que é por meio das características e práticas desse processo que ocorrem todas as ações do processo educacional.

\section{Metodologia}

Caracteriza-se como uma pesquisa de natureza aplicada. Segundo Prodanov e Freitas (2013, p. 51), "objetiva gerar conhecimentos para aplicação prática dirigidos à solução de problemas específicos. Envolve verdades e interesses locais". De acordo com o problema a ser investigado, a abordagem é predominantemente qualitativa e descritiva (GIL, 2016).

As fontes de coleta de dados foram selecionadas a partir da compreensão de que o conhecimento e prática em torno do eixo "gestão educacional" pudessem ser identificados com a condição de garantirem dados fidedignos. Diante disso, foi selecionada uma instituição federal de Ensino Superior do Estado do Rio Grande do Sul, Brasil, que ofertasse o curso de Pós-Graduação em Gestão Educacional.

Os estudantes desse curso foram os participantes, 21 discentes, representando aproximadamente $68 \%$ da turma do curso de Pós-Graduação em Gestão Educacional, edição 2019/1. O número de aprovados na seleção para esse curso foram 35, com duas suplências, porém, após o período de confirmação de vagas e matrículas, 31 estudantes efetivaram matricula e, destes 31, não houveram desistências informadas à secretaria/coordenação do curso, dessa forma todos ainda constam com matrícula ativa e vínculo junto à Instituição.

RPGE- Revista on line de Política e Gestão Educacional, Araraquara, v. 25, n. 2, p. 1264-1281, maio/ago. 2021. e-ISSN: 1519-9029 
Para além do critério de seleção ser a participação em um curso de gestão, inferiu-se que a pós-graduação alia o profissional em busca de formação continuada. Assim, os estudantes do curso, via de regra, já são profissionais na área da educação, o que poderia qualificar as condições e análise dos dados levantados.

O instrumento de coleta de dados constituiu-se de um questionário de avaliação do curso, adaptado de Bertolin e Marchi (2010, p. 142), fundamentado em um sistema de indicadores de avaliação. O questionário apresenta 13 questões, abrangendo três categorias de análise, que foram definidas a priori, pois constituem o questionário. Considerando os três momentos fundamentais na realização de uma formação acadêmica: entrada, processo e resultados. Os discentes avaliaram as questões de maneira quantitativa, sinalizando o grau de satisfação (ótimo, bom, regular, ruim, péssimo).

Para a análise dos resultados utilizou-se como referência a análise de conteúdo proposta por Bardin (2011). No conjunto das técnicas da análise de conteúdo empregou-se a análise por categorias, elencando três: entrada, processo e resultados. De modo geral, o funcionamento e o objetivo da análise de conteúdo podem resumir-se da seguinte maneira, um conjunto de técnicas de análise visando obter por procedimentos sistemáticos e objetivos de descrição do conteúdo que permitam a inferência de conhecimentos relativos às variáveis inferidas dessas mensagens (BARDIN, 2011).

O questionário foi aplicado on-line, por meio do Formulário Google, com envio de um link para o questionário. Os 21 participantes eram todos professores em exercício e ao aceitarem participar da pesquisa estavam cientes dos objetivos e procedimentos do estudo, haja vista que tiveram acesso anterior ao questionário e ao Termo de Consentimento Livre e Esclarecido (TCLE), que aporta todos os cuidados com a ética na pesquisa com seres humanos.

Os dados de campo foram coletados por meio do Projeto Educação, Saúde e Inclusão 3. ed., registrado no Gabinete de Projetos- GAP com o Número 053283 e com aprovação no Comitê de ética e registro CAAE:27550820.3.0000.5346.

\section{Resultados e discussões}

O processo de avaliação das Instituições de Ensino Superior está cada vez mais presente nas universidades, o qual remete invariavelmente à qualidade da educação do país. É um tema complexo e de importância nas abordagens, projetos e práticas educacionais. 
Ressalta-se que, a avaliação é vista como um instrumento de gestão para a melhoria contínua dos cursos/programas, contando com a participação da sociedade.

Assim, pode-se dizer que é possível avaliar a qualidade em educação por meio de "um conjunto de atributos, aspectos ou indicadores acerca das entradas, processo e resultados educativos, ou das relações entre eles" (BERTOLIN; MARCHI, 2010, p. 134).

Diante disso, a primeira categoria de análise, Entrada, contemplou questões relacionadas à infraestrutura do curso, planejamento das disciplinas e habilidades dos participantes. O instrumento de avaliação utilizado continha 13 questões, distribuídas entre as três categorias que deveriam ser respondidas a partir de uma escala disposta do ótimo ao péssimo (ótimo, bom, regular, ruim e péssimo).

A avaliação da infraestrutura do curso de pós-graduação foi realizada sob o olhar dos discentes que ingressaram no curso no primeiro semestre de 2019. Dos 21 alunos concluintes, 13 avaliaram os ambientes/softwares de aprendizagem e demais recursos tecnológicos utilizados no transcorrer das disciplinas como "boa", representando 61,9\% dos participantes; quatro professores demonstraram descontentamento ao apontar como "regular" (19\%); três indicaram "ótimo" (14,3\%); e um professor expressou insatisfação ao sinalizar "ruim" (4,8\%). Com isso, percebe-se que muitos recursos, especificamente relacionados às tecnologias educacionais, necessitam de melhorias e aprimoramentos quando inseridos nas aulas.

Figura 1 - Infraestrutura do curso de Especialização
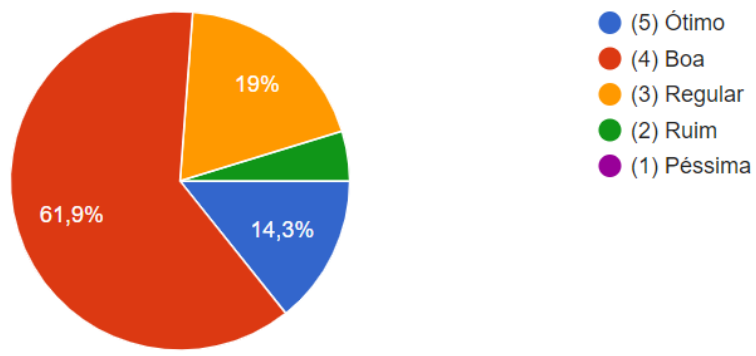

Fonte: Elaborado pelos autores

Segundo Marback Neto (2007, p. 171), a avaliação institucional "é um poderoso e imprescindível instrumento gerencial e pedagógico que envolve aferição, revisão e construção". Nesse sentido, a avaliação realizada pelos gestores educacionais em processo de conclusão de curso fornece subsídios para os processos de tomada de decisão e implementação de resultados para a melhoria contínua do curso. 
A segunda questão, referente às habilidades e competências dos docentes para desenvolvimento das disciplinas, foi avaliada por $42,9 \%$ (nove alunos) como "boas", $28,6 \%$ (seis professores) demonstraram-se satisfeitos ao sinalizarem a opção "ótimas" e os 28,6\% restantes (seis discentes) revelaram-se descontentes ao indicar a alternativa "regulares". Quanto às habilidades docentes, Lowman (2007), descreveu como bom professor universitário aquele que possui habilidade de criar um estímulo intelectual e empatia interpessoal com seus estudantes. Essas duas habilidades são relativamente independentes, em contrapartida, a efetividade de uma dessas categorias pode gerar êxito no magistério superior. No entanto, quando um professor faz uso das duas habilidades, possui a probabilidade de ser considerado excelente em qualquer ambiente de ensino.

Figura 2 -Competências e habilidades dos professores no desenvolvimento das disciplinas

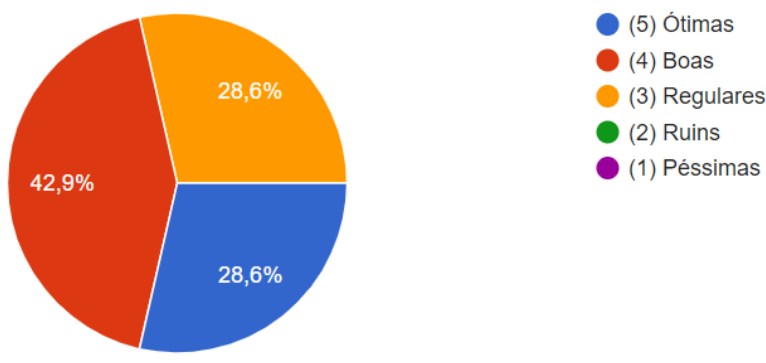

Fonte: Elaborado pelos autores

Na sequência os participantes avaliaram suas habilidades de uso do computador ao ingressarem no curso. Pode-se observar que 71,4\% (15 professores) indicaram sendo "boas", três alunos (14,3\%) "ótimas" e três $(14,3 \%)$ assinalaram suas habilidades "regulares". Evidencia-se com esse resultado que os professores em formação, ao realizarem sua práxis pedagógica na sala de aula e ao se depararem com entraves, devem encontrar soluções para o tratamento desses. 
Figura 3 - Habilidades de uso de computador ao ingressar no curso

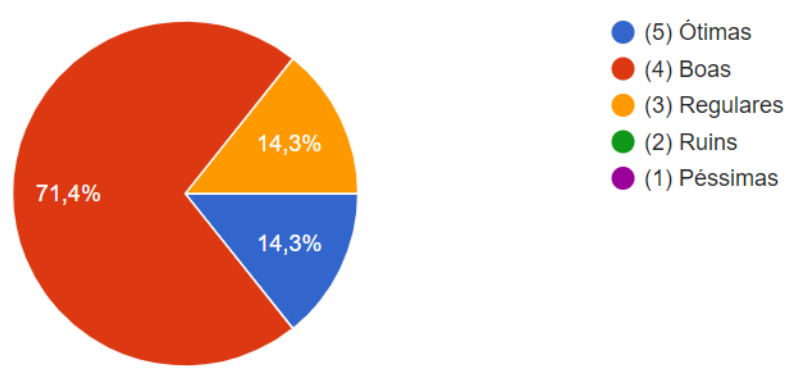

Fonte: Elaborado pelos autores

Entende-se que o uso do computador como recurso didático enriquece as situações de aprendizagem e elaboração do saber, colaborando para que o conhecimento adquira um grau maior de significação, ampliando oportunidades e, com isso, destacando o potencial das TIC no contexto educacional.

Quando o questionamento foi sobre o planejamento realizado pelos professores na oferta das disciplinas, incluindo plano de ensino, carga horária do ensino a distância (EaD), material didático, bibliografia e mídias utilizadas, os resultados obtidos apontam que seis discentes $(28,6 \%)$ avaliaram o planejamento "ótimo", 11 pontuaram "bom" $(52,4 \%)$ e quatro professores "regular" (19\%).

Figura 4 - O planejamento realizado pelos professores para as disciplinas

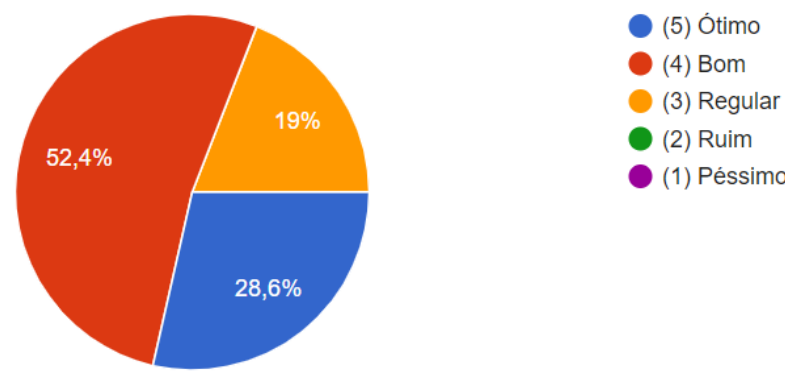

Fonte: Elaborado pelos autores

Um aspecto positivo a respeito desse resultado está na valorização e reconhecimento do trabalho produzido pelos docentes do curso. O planejamento de ensino não é apenas função dos professores, mas de todo o segmento universitário e acadêmico que contribuem para ampliar o conhecimento (coordenação, secretaria, colegiado, reitoria). Os procedimentos, planejamentos e metodologias de ensino são resultantes dessas práticas interdisciplinares.

RPGE- Revista on line de Política e Gestão Educacional, Araraquara, v. 25, n. 2, p. 1264-1281, maio/ago. 2021. e-ISSN: 1519-9029 
A segunda categoria de análise, denominada Processo, refere-se ao contexto pedagógico e organizacional, portanto são aquelas características relativas às "horas de ensino, dedicação dos docentes, acesso e utilização das TIC podem compor a estrutura dos indicadores de processo" (BERTOLIN; MARCHI, 2010, p. 135).

Nessa categoria foi avaliada a interação dialógica desenvolvida entre professor-aluno durante o curso de pós-graduação. Como resultado seis estudantes $(28,6 \%)$ avaliaram a interação dialógica como "ótima", 12 sinalizaram a interação "boa" $(57,1 \%)$ e três discentes pontuaram "regular" $(14,3 \%)$. Colaborando com essa discussão, Freire $(1987$, p. 93$)$ ressalta o diálogo como "o encontro entre os homens, mediatizados pelo mundo para pronunciá-lo". Com isso, apresenta uma pedagogia baseada no processo de conscientização crítica da realidade. Ao encontro disso, instaura-se o desafio de superar a contradição entre opressoroprimido, pois muitas vezes o oprimido tende a hospedar em si a ideologia do opressor, de um dia se parecer com ele, aderir sua postura, atitudes, gostos.

Figura 5 - Interação dialógica desenvolvida entre professor-aluno durante o curso

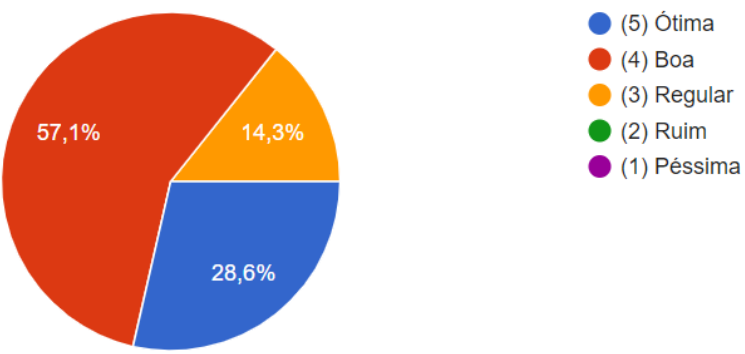

Fonte: Elaborado pelos autores

Quanto as orientações prestadas durante o curso, percebe-se que somente três professores (14,3\%) não se sentiram satisfeitos ao marcarem a alternativa "regulares", ademais nove discentes (42,9\%) concluíram como "ótimas" e outros nove avaliaram como "boas" (42,9\%). Sobre essa questão, Freitas e Souza (2018, p. 132) discutem as relações entre pesquisa, formação e produção de conhecimento presentes no trabalho de orientação. Assim, o processo de orientação produz efeitos na decisão e definição de três aspectos que implicam no desenvolvimento interacional entre orientadores e orientandos, "o conteúdo temático da pesquisa, o ritmo do trabalho a ser desenvolvido e o modo de organizar o trabalho". Tornar-se orientador, na maioria das vezes, ainda é "resultado de trajetórias pessoais com os próprios orientadores, por modelação, por experiências de eliminação do que foi vivido negativamente, ou até por formas de (re)afirmação de sua autoridade" (FREITAS; SOUZA, 2018, p. 139). 
Figura 6 - Orientações prestadas durante o desenvolvimento da monografia

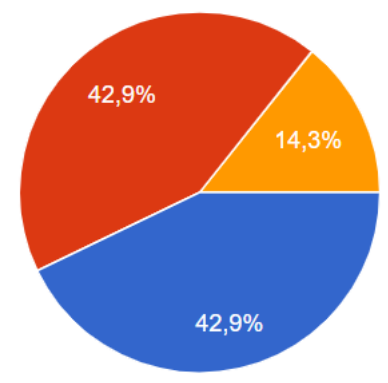

(5) Ótimas

(4) Boas

(3) Regulares

(2) Ruins

(1) Péssimas

Fonte: Elaborado pelos autores

O suporte técnico-administrativo prestado durante o curso é evidenciado ao considerar que sete professores avaliaram como "ótimo", representando 33,3\% dos participantes. Onze professores $(52,4 \%)$ em formação consideraram "bom" o desempenho técnico-administrativo e três "regular" $(14,3 \%)$, devido à demora nos retornos de e-mails e dúvidas referentes ao curso, como dispensa de disciplinas.

Figura 7 - Suporte técnico-administrativo prestado durante a Especialização
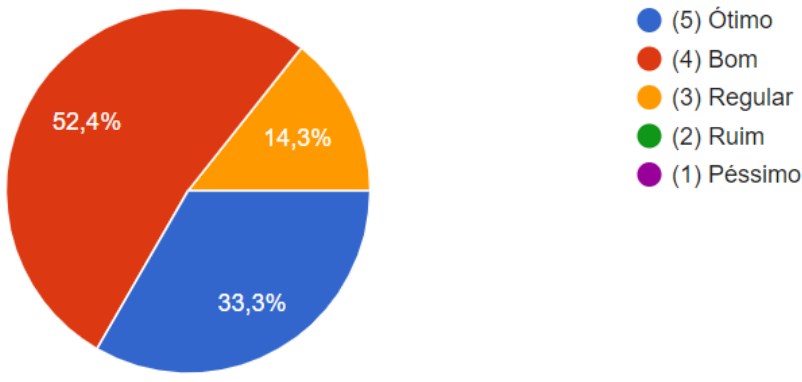

Fonte: Elaborado pelos autores

Quanto à articulação e adequação entre os momentos presencial e à distância percorridos nas disciplinas, quatro estudantes sinalizaram "ótima" (19\%), 15 apontaram que a articulação foi "boa" (71,4\%) e dois professores avaliaram como "regular" $(9,5 \%)$. Com isso, a combinação do ensino presencial com a aprendizagem remota e/ou on-line, conhecida como ensino híbrido, uma das principais tendências do século 21, possibilita aos estudantes "aprender a qualquer momento, em qualquer lugar, em qualquer caminho, em qualquer ritmo" (HORN; STAKER, 2015, p. 10). 
Figura 8 - Articulação e adequação entre os momentos presencial e à distância (conteúdos e carga horária) das disciplinas
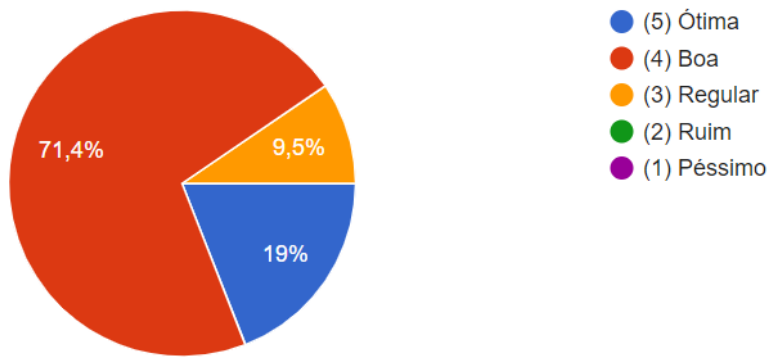

Fonte: Elaborado pelos autores

Nesta direção, se destaca que o Brasil possui apenas duas formas de credenciamento institucional, o ensino presencial e ensino a distância (EaD). Nesse sentido, conforme a Portaria $n^{\circ}$ 2.117/2019 (BRASIL, 2019) que autoriza as instituições de Ensino Superior (IES) a ampliar para até $40 \%$ a carga horária de $\mathrm{EaD}$ em cursos presenciais de graduação, devido a atual pandemia Coronavírus (Covid-19), a expectativa é a redução de custos das Instituições de Ensino Superior (IES), como consequência da diminuição do uso do espaço físico, energia elétrica, limpeza, água, entre outros.

Contudo, o Ministério da Educação (MEC) ao publicar a Portaria $n^{0}$ 343/2020 (BRASIL, 2020) que objetiva dar seguimento ao processo de ensino-aprendizagem durante o período da pandemia do Coronavírus (Covid-19), determinando a substituição das aulas presenciais por aulas que utilizem meios e tecnologias da informação e da comunicação, neste artigo denominadas de aulas remotas, reforça que as práticas de ensino híbrido visam uma educação em perspectiva integral para o século XXI, impulsionando o desenvolvimento da autonomia, da aprendizagem e do protagonismo na aprendizagem. Constatou-se que $71,4 \%$ dos alunos avaliaram essa articulação das aulas presenciais e a distância como "boa", de modo geral isso demonstra que a adesão é positiva, tanto aos conteúdos quanto à carga horária das disciplinas. Em outras palavras, o ensino híbrido flexibiliza o processo de ensino e aprendizagem e é visto com otimismo.

Por conseguinte, os discentes realizaram a avaliação da prática didático-pedagógica desenvolvida pelos docentes do curso nas aulas presenciais. Identificou-se que seis participantes julgaram a prática "ótima" $(28,6 \%)$, nove classificaram "boa" $(42,9 \%)$ e seis consideraram "regular" (28,6\%). Nesse aspecto, Franco (2016, p. 536) conceitua uma prática pedagógica "como uma ação consciente e participativa, que emerge da multidimensionalidade 
que cerca o ato educativo". Ou seja, objetiva atender determinadas expectativas educacionais, pois uma prática pedagógica é a prática da didática.

Figura 9 - A prática didático-pedagógica desenvolvida pelo professor na aula presencial
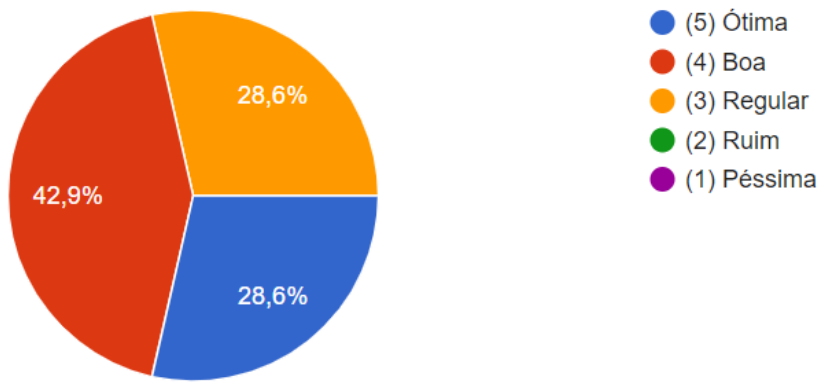

Fonte: Elaborado pelos autores

Dessa forma, o sentido da didática é o da produção da aprendizagem nos estudantes, por meio de processos de ensino previamente planejados. Em suma, o professor, no exercício de sua prática docente, pode ou não se exercitar pedagogicamente. Ou seja, "sua prática docente, para se transformar em prática pedagógica, requer, pelo menos, dois movimentos: o da reflexão crítica de sua prática e o da consciência das intencionalidades que presidem suas práticas" (FRANCO, 2016, p. 543).

Ao passo que $28,6 \%$ dos discentes consideraram a prática dos professores "regular", faz-se necessário pensar em soluções, rever os planos de ensino, as metodologias utilizadas e até mesmo considerar uma autoavaliação docente, visando um aperfeiçoamento da sua prática pedagógica. Entretanto, este exercício requer professores capazes de compartilhar com seus colegas a responsabilidade pela melhoria do seu próprio desempenho.

Todavia, o professor não transforma a sala de aula sozinho, as práticas pedagógicas funcionam como espaço de diálogo, com a existência de um grupo, interagindo por meio de trocas mútuas, consequentemente construindo conhecimento. Por conseguinte, na avaliação da aprendizagem discente no curso de pós-graduação, três alunos a consideraram "ótima" (14,3\%), 14 discentes julgaram "boa" (66,7\%), três estudantes "regular" (14,3\%) e um professor demonstrou sua insatisfação ao marcar a alternativa "ruim" $(4,8 \%)$. 
Figura 10 - Avaliação da aprendizagem desenvolvida no curso

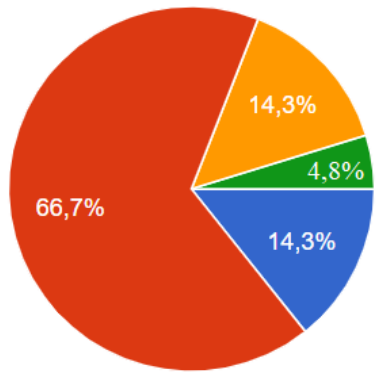

$$
\begin{aligned}
& \text { (5) Ótima } \\
& \text { (4) Boa } \\
& \text { (3) Regular } \\
& \text { (2) Ruim } \\
& \text { (1) Péssima }
\end{aligned}
$$

Fonte: Elaborado pelos autores

Frente às questões abordadas, a autoavaliação do aluno se torna um método fundamental na avaliação do curso, pois traz um feedback consciente sobre a trajetória que os aprendizes percorreram, seu desenvolvimento intelectual, aquisição de habilidades, atitudes, auxiliando os professores e gestores na tomada de decisão. Destaca-se preocupação em relação aos estudantes que demonstraram insatisfação, resultando em um total de 19,1\% que sinalizaram a aprendizagem como "regular" e "ruim".

Por fim, a terceira e última categoria de análise, Resultados, propõe indicadores a serem considerados, sobre os objetivos alcançados. Assim, a aprendizagem, o desenvolvimento de habilidades, autonomia, iniciativa, organização do tempo de estudo. (BERTOLIN; MARCHI, 2010). Com base nesses indicadores, é possível avaliar a qualidade das disciplinas em cursos semipresenciais.

A avaliação da aprendizagem e aproveitamento nas disciplinas do curso de pósgraduação nessa categoria resultou em dois discentes que indicaram sua aprendizagem e seu aproveitamento como "ótimo" (9,5\%), 18 alunos consideraram "boa", representando 85,7\% dos participantes, e um discente avaliou como "ruim" $(4,8 \%)$.

Figura 11 - Avaliação da aprendizagem e aproveitamento das disciplinas do curso
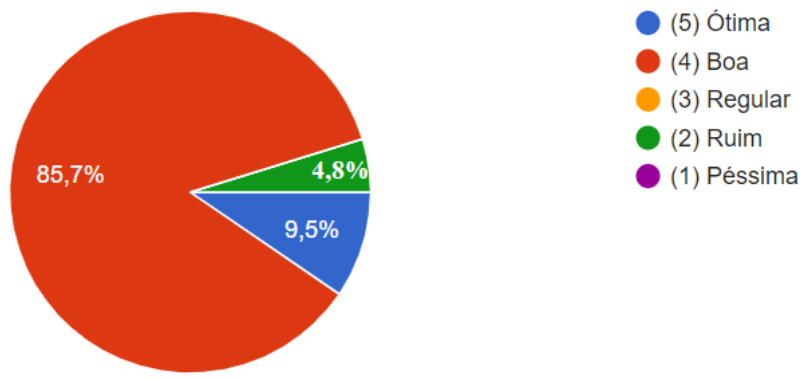

(1) Péssima

Fonte: Elaborado pelos autores 
Independente do modelo de avaliação adotado nas universidades em cursos de graduação e pós-graduação, Franco (1997) sugere que deve haver uma redefinição, considerando o vínculo social e histórico do aluno, priorizando assim a objetividade, sem descartar a subjetividade. Por um lado, deve-se considerar o aluno como parte integrante de uma estrutura social que tem uma parcela de influência no seu rendimento acadêmico. Por outro, o professor deve conhecer os motivos e objetivos da avaliação para que, com o resultado do processo avaliativo, discuta com o discente, por meio de feedbacks uma alternativa para melhorar o desempenho de ambos. Sendo assim, um dos principais objetivos da avaliação é verificar o progresso do aluno no processo de ensino e aprendizagem.

Considerando que $85,7 \%$ dos participantes avaliaram sua aprendizagem e aproveitamento nas disciplinas como "boa", constatou-se que a principal contribuição da autoavaliação foi efetivada, confirmando sua validade. Ou seja, verificar se a metodologia escolhida alcançou os objetivos propostos, se foi a mais adequada e oportunizou o acesso ao conhecimento.

Em relação ao desenvolvimento de habilidades no uso de TIC durante o curso, dois discentes $(9,5 \%)$ julgaram o desenvolvimento de suas habilidades como "ótimo", 15 alunos $(71,4 \%)$ consideraram "bom" e quatro professores como "regular" $(19 \%)$. Considerando a necessidade de promover a educação com o uso de TIC e de maximizar a utilização dos recursos disponíveis, alguns problemas encontrados como a falta de tempo extraescolar dos alunos da pós-graduação, a dificuldade em acessar o ambiente virtual de aprendizagem (AVA) somado à restrição de horários para uso do laboratório de informática, produzem déficit de satisfação aos acadêmicos. Nesse sentido, infere-se que a alfabetização digital e o desenvolvimento de habilidades e competências no uso de TIC, possam ser desenvolvidas pelos professores.

Figura 12 - Desenvolvimento de habilidades no uso de TIC no transcorrer do curso

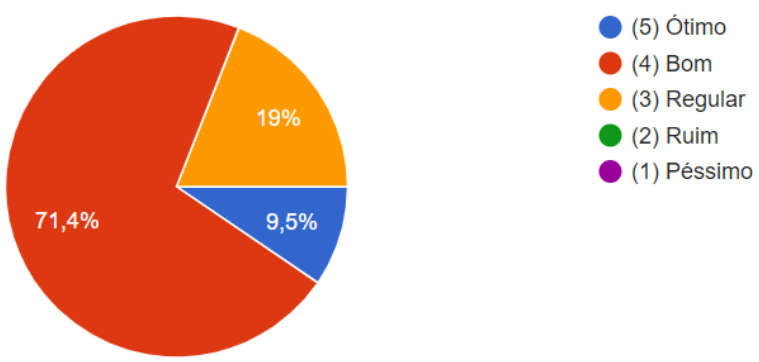

Fonte: Elaborado pelos autores 
Os questionamentos sobre a avaliação dos alunos, que encerra os questionamentos, incluem: desenvolvimento da capacidade de autonomia e de auto-organização (tempo) durante o transcorrer do curso. Dois alunos indicaram "ótimo" (9,5\%), 15 discentes avaliaram o seu desenvolvimento como "bom" $(71,4 \%)$ e quatro professores julgaram sua capacidade "regular" (19\%).

Figura 13 - Desenvolvimento da capacidade de autonomia e auto-organização
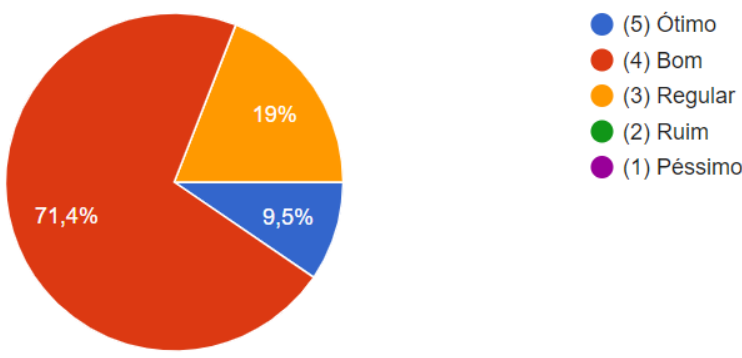

Fonte: Elaborado pelos autores

A ideia de autonomia pode ser identificada com a defesa da auto-organização. Para Pistrak (2009), a auto-organização (autodireção) dos estudantes pode ser revelada em três capacidades, sendo elas: a habilidade de trabalhar coletivamente, habilidade de trabalhar organizadamente cada tarefa e desenvolvimento da capacidade criativa.

Segundo o autor, promover a auto-organização exige que os estudantes passem “[...] por uma variedade de formas organizacionais, o que pode ser conseguido dando-se à autoorganização formas mais flexíveis, que se adaptem cada vez às novas tarefas" (PISTRAK, 2009, p. 123). Da mesma forma, destaca-se a importância da autonomia docente, pois ambos, professores e alunos, são sujeitos da prática educacional.

Por fim, a maioria das atividades e trabalhos realizados durante o curso exigia trabalho em equipe, o que pode ser uma das justificativas dos $19 \%$ dos participantes terem julgado sua capacidade como regular, devido ao fato de terem dificuldade em realizar trabalho de forma colaborativa, necessitando de uma adaptação, auto-organização.

\section{Relação entre entrada, processo e resultado}

Ao relacionar as três categorias foi possível verificar aspectos que são fundamentais, pois Bertolin e Machi (2010) reforçam que a comparação entre os indicadores de resultados e os aspectos de entrada e processo e entre a avaliação de um sujeito interessado e a 
autoavaliação de outros sujeitos envolvidos, incorpora aspectos de autovalidação. Dessa forma, como sugestão para trabalhos futuros, seria importante também a participação do corpo docente, pois permitiria uma completa avaliação do curso de pós-graduação acerca do uso das TIC.

Do mesmo modo, é importante destacar que o curso de gestão educacional foi avaliado pelos participantes como "bom", havendo empate somente na questão referente às orientações prestadas pelos docentes durante o transcorrer do curso (ótimo 42,9\% e bom 42,9\%).

Ademais, foi possível observar que todos os indicadores presentes no instrumento de avaliação do curso, em sua totalidade, foram considerados "bom". Com isso, emergem questões para reflexão e análise que poderiam ser debatidas futuramente com egressos, professores e equipe gestora do curso, tais como, o que estaria faltando para ser considerado ótimo? Quais melhorias são sugeridas?

\section{Considerações finais}

Este estudo teve como objetivo avaliar a contribuição das TIC na gestão educacional, concluindo que as TIC são ferramentas importantes para a educação e a tendência é de que elas possam ser utilizadas cada vez mais nas práticas de ensino e aprendizagem, uma vez que constituem meios para o desenvolvimento da inteligência coletiva, promovendo inovação, interação, criação de conteúdo e aprendizagem colaborativa.

O uso de recursos tecnológicos nos processos de ensino e aprendizagem favorece a motivação na aquisição de habilidades em TIC quando adotadas as ferramentas adequadas a cada nível de ensino e conteúdo a serem aprendidos. Alguns recursos de tecnologias educacionais necessitam de aprimoramentos quando inseridos nas aulas, pois apenas o investimento na compra de recursos tecnológicos não ocasiona mudanças no processo educacional. É necessário também o desenvolvimento profissional do corpo docente para a utilização pedagógica e crítica das tecnologias digitais, a fim de provocar mudanças e reflexões significativas.

Acredita-se que a formação do gestor educacional, por meio do uso das TIC, poderá transformar sua práxis enquanto administrador, de modo a desenvolver novas propostas de gestão ao utilizar os recursos tecnológicos permeados por uma abordagem interdisciplinar e democrática, favorecendo a participação dos partícipes do processo.

Com isso, o uso das TIC na educação poderá ressignificar a prática do professor enquanto gestor, administrador e pessoa. Possivelmente, essa é uma das contribuições do 
estudo, demarcar um avanço no conhecimento científico que implica na necessidade de intensificar e impor o uso das TIC no ambiente educacional, até então, considerado de uso opcional.

Por conseguinte, espera-se, que a pesquisa integre os subsídios empíricos e teóricos para se discutir e refletir o processo de gestão, avaliação e uso de TIC, em uma nova era da educação, em que o protagonismo da TIC se evidenciou imposto pelas condições sanitárias mundiais, mas que tende a ficar.

Por fim, a contribuição do estudo realizado não teve a pretensão de esgotar as discussões referentes ao tema assumindo as limitações que são identificadas nas pesquisas aplicadas, mas despertar a possibilidade de desenvolvimento de novos objetos de investigação. Assim como evidenciar a importância das TIC na consolidação do conhecimento e apontar o seu potencial para auxiliar os professores e gestores escolares nas tarefas do dia a dia e evidenciar a necessidade de sua aplicação, auxiliando sua prática docente e promovendo a inclusão digital, motivação os alunos e professores no processo de ensino e aprendizagem.

\section{REFERÊNCIAS}

BARCELOS, G. T.; PASSERINO, L. M.; BEHAR, P. A. Redes sociais na internet: ambiente pessoal de aprendizagem na formação de professores iniciantes de matemática. Revista Novas Tecnologias na Educação, Porto Alegre (RS), v. 9, n. 1, p. 1-10, 2011. Disponível em: https://seer.ufrgs.br/renote/article/view/21902/12706. Acesso em: 15 jun. 2019.

BARDIN, L.; Análise de conteúdo. São Paulo, SP: Edições 70, 2011.

BERTOLIN, J. C. G.; MARCHI, A. C. B. Instrumentos para avaliar disciplinas da modalidade semipresencial: uma proposta baseada em sistemas de indicadores. Avaliação, Campinas (SP), v. 15, n. 3, p. 131-146, 2010. Disponível em:

https://www.scielo.br/j/aval/a/KHsWbwwT6W8sKRY7mbhb7sJ/?lang=pt\&format=pdf. Acesso em: 20 ago. 2019.

BRASIL. Constituição (1988). Constituição da República Federativa do Brasil de 1988. Brasília, DF: Senado Federal, 2016. Disponível em: http://www.planalto.gov.br/ccivil_03/constituicao/constituicaocompilado.htm. Acesso em: 30 jul. 2020.

BRASIL. Lei n. 9.394, de 20 de dezembro de 1996. Diretrizes e Bases da Educação Nacional. Brasília, DF, 23 dez. 1996. Disponível em: http://www.planalto.gov.br/CCIVil_03/LEIS/19394.htm. Acesso em: 10 jun. 2019.

BRASIL. Portaria n. 2.117, de 6 de dezembro de 2019. Dispõe sobre a oferta de carga horária na modalidade de Ensino a Distância - EaD em cursos de graduação presenciais 
ofertados por Instituições de Educação Superior - IES pertencentes ao Sistema Federal de Ensino. Brasília, DF, 11 dez. 2019. Disponível em: https:/www.in.gov.br/en/web/dou//portaria-n-2.117-de-6-de-dezembro-de-2019-232670913. Acesso em: 21 ago. 2020.

BRASIL. Portaria n. 343, de 17 de março de 2020. Dispõe sobre a substituição das aulas presenciais por aulas em meios digitais enquanto durar a situação de pandemia do Novo Coronavírus - COVID-19. Brasília, DF, 18 mar. 2020. Disponível em:

https://www.in.gov.br/en/web/dou/-/portaria-n-343-de-17-de-marco-de-2020-248564376. Acesso em: 21 ago. 2020.

DIAS, E. P. Conceitos de gestão e administração: uma revisão crítica. Revista Eletrônica de Administração, São Paulo (SP), v. 1, p. 1-12, 2002. Disponível em:

https://periodicos.unifacef.com.br/index.php/rea/article/view/160/16. Acesso em: 25 jul. 2019.

DOURADO, L. F. Progestão: como promover, articular e envolver a ação das pessoas no processo de gestão escolar? Brasília, DF: CONSED - Conselho Nacional de Secretários de Educação, 2001.

FRANCO, M. A. R. S. Prática pedagógica e docência: um olhar a partir da epistemologia do conceito. Revista Brasileira de Estudos Pedagógicos, Brasília (DF), v. 97, n. 247, p. 534551, 2016. Disponível em:

https://www.scielo.br/j/rbeped/a/m6qBLvmHnCdR7RQjJVsPzTq/?lang=pt\&format=pdf. Acesso em: 20 set. 2019.

FRANCO, M. L. P. B. Pressupostos epistemológicos da avaliação educacional. In: SOUZA, C. P. (Org.) Avaliação do rendimento escolar. 6. ed. Campinas, SP: Papirus, p. 13-26, 1997.

FREIRE, P. Pedagogia do oprimido. 17. ed. Rio de Janeiro, RJ: Paz e Terra, 1987.

FREITAS, M. F. Q.; SOUZA, J. Formação em pesquisa na pós-graduação: possibilidades e desafios a partir da orientação. Educar em Revista, Curitiba (PR), v. 34, n. 71, p. 125-141, 2018. Disponível em:

https://www.scielo.br/j/er/a/TM3J9mfsxQJW797k5MfMhqb/?format=pdf\&lang=pt. Acesso em: 21 set. 2019.

GIL, A. C. Métodos e técnicas de pesquisa social. 6. ed. 7. reimpr. São Paulo, SP: Atlas, 2016.

HORN, M. B.; STAKER, H. Blended: usando a inovação disruptiva para aprimorar a educação. Porto Alegre, RS: Penso, 2015.

LOWMAN, J. Dominando as técnicas de ensino. São Paulo, SP: Atlas, 2007.

MARBACK NETO, G. Avaliação: instrumento de gestão universitária. Vila Velha, ES: Hoper, 2007.

PISTRAK, M. M. A escola comuna. São Paulo, SP: Expressão Popular, 2009. 
PRODANOV, C. C.; FREITAS, E. C. Metodologia do trabalho científico: métodos e técnicas da pesquisa e do trabalho acadêmico. 2. ed. Novo Hamburgo, RS: Universidade FEEVALE, 2013.

\section{Como referenciar este artigo}

THEISEN, G. R.; PAVÃO, S. M. O.; PAVÃO, A. C. O. TIC na gestão educacional: efetividade na academia. Revista on line de Política e Gestão Educacional, Araraquara, v. 25 , n. 2, p. 1264-1281, maio/ago. 2021. e-ISSN:1519-9029. DOI: https://doi.org/10.22633/rpge.v25i2.14576

Submetido em: $18 / 12 / 2020$

Revisões requeridas em: 28/05/2021

Aprovado em: 15/06/2021

Publicado em: 01/08/2021 